International Journal of Social Science And Human Research

ISSN(print): 2644-0679, ISSN(online): 2644-0695

Volume 04 Issue 12 December 2021

DOI: $10.47191 / \mathrm{ijsshr} / \mathrm{v} 4-\mathrm{i} 12-34$, Impact factor-5.586

Page No: 3697-3703

\title{
Examination of the Predictability of Psychological and Sociodemographic Variables among Early Emerging Adulthood and Late Emerging Adulthood Seeking Mental Health Treatment
}

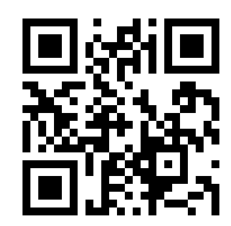

\author{
Çisem Uzun ${ }^{1}$, Hüseyin Ünübol², Gökben Hızlı Sayar ${ }^{3}$ \\ ${ }_{1,2,3}$ Üsküdar University, Institute of Social Science, Psychology İstanbul-Turkey
}

\begin{abstract}
In this study, the relationship between psychiatric symptoms and the use of mental services among 18-29-year-old adults was examined. Data were collected from the 18-29 aged men and women whos participated in the TURBAHAR study. Psychological symptoms, attachment, alexithymia, personal well-being, and positive-negative mood levels of the participants were examined for the research. According to the regression analysis, it was found that smoking and alcohol use, depression, personal well-being, and hostility levels significantly predicted the psychiatric status of both women and men. In addition, it was found that negative self-esteem and somatization levels predicted the use of mental health services among women. The results showed that more psychological factors were affecting the use of mental health services for women compared to men. The findings are expected to contribute to the structuring of services for men and women in terms of the utilization of mental health services based on gender differences.
\end{abstract}

KEYWORDS: Psychiatric Symptoms, Depression, Anxiety, Hostility, Somatization, Negative Self, Dependence.

\section{INTRODUCTION}

Approximately $70 \%$ to $75 \%$ of mental health problems begin in early emerging adulthood and late-emerging adulthood. Worldwide, mental health problems account for one-third of the burden of disease in adolescents and early adults. [1] Mental health problems and psychiatric disorders lead to dysfunctions in school, work, and social relations, a decrease in quality of life, and the formation of medical conditions that can be associated with mental health. [2] Even though the majority of the burden of illness among early emerging adulthood and late-emerging adulthood worldwide constitutes psychiatric disorders, they can avoid benefiting from the mental health services they need. [3]

The most widespread research in psychiatric disorders is that there is a gender difference in seeking psychiatric treatment or seeking mental health. [4] In the study, it was stated that women seek more mental health treatment than men, and the primary factor is the cultural gender roles. Characteristics of gender roles include the role of women as socio-emotional leaders in the family and the duties and responsibilities of maintaining the well-being of the family. [4] In addition, "Theory of Planned Behavior" is the background of men seeking help for mental health problems compared to women and having fewer applications. Under the aforementioned theory, men do not want to eliminate the ideology of traditional gender roles or avoid conflict of the gender roles. This status leads to negative attitudes of men towards seeking help for mental health problems.

Mechanic [5] defined health behaviors of individuals as actions for health towards somatic or emotional status. This concept includes cognitive, behavioral, and affective processes related to disorders. In this respect, it is stated that the differentiation of health behaviors according to gender is not merely related to biological differences also related to role demands and especially the unequal conditions of women. In studies conducted on psychiatric disorders in which men and women benefit from mental health services, it is stated that women seek more psychiatric treatment for mood disorders and anxiety disorders than men. [6] On the other hand, it was found that men and women were equal in seeking treatment for alcohol and substance use and addiction disorders; however, it is suggested that women are more prepared for change than men. [7]

The implications for seeking solutions and treatment of health behaviors and disorders of women and men are that the burden of disease is higher and women need more care, and both genders are more aware of women's symptoms due to differences in socio-emotional skills. For example, the differences are the need for more and the need to delay the treatment of complaints and the fact that women express their complaints easier than men. [8]

Among the studies that provide evidence that men benefit less from mental health services than women do, Hansen and Høye [9] conducted a cross-sectional study to examine the level of utilization of outpatient psychiatric treatment services in Norway. Psychiatric diagnosis and treatment applications of 12982 participants were examined. According to the results of the study, 


\section{Examination of the Predictability of Psychological and Sociodemographic Variables among Early Emerging Adulthood and Late Emerging Adulthood Seeking Mental Health Treatment}

anxiety or depression symptoms were found in $21.5 \%$ and $12.3 \%$ of men. $4.6 \%$ and $3.3 \%$ of males receive outpatient psychiatric treatment for one year.

In another study which 387 women participated conducted by Gür and Küçük [10]. The socioeconomic levels of the participants were at the middle-lower level. According to the study whose sample has not detected the prevalence of the psychiatric disorder, older and married women were found to have a more positive attitude towards mental health problems and their solutions. In addition, it was found that the attitudes of the people with higher socioeconomic status to mental health problems were negative compared to the people with low socioeconomic levels.

When considering studies and related literature are examined, and within the mind of the evaluation of the views of adult individuals in different regions of our country regarding psychiatric treatment can provide information on the level of mental health literacy within the scope of TURBAHAR study. This study aimed to investigate the psychological symptoms of early emerging adulthood and late-emerging adulthood grouped according to demographic information and psychiatric treatment status. Moreover, it aimed to understand which psychological symptoms and demographic variables are gender, alcohol and cigarette use, and whether participants are more likely to seek psychiatric treatment.

\section{METHODS}

In this section, the research's aim and the universe, the sample, the procedure, the research's used data collection tools, and the evaluation of the data have been given.

\subsection{Research Universe, Sample and Procedure}

\subsubsection{Research Universe:}

Turkey Addiction Risk Profile and Mental Health Map (TURBAH's) used for sample design and size, across Turkey, and 9 demographic regions (Mediterranean, Aegean, Black Sea, Eastern Black Sea, Eastern Anatolia, Central Anatolia, western Marmara, eastern Marmara, Istanbul) analysis. In the sample selection of TURBAHAR, a stratified cluster sampling approach was used. At least 200 and at most 2000 people from each region were included. The criteria included are volunteers over 18 years of age, and no problems preventing the completion of questionnaires.

\subsubsection{Research Sample:}

This study was conducted with 12942 people between the ages of 18-29 involved in Turkey's Addiction and Mental Health Map (TBRSH). Participants included in the study were 18-29 years old, and 50.7\% were women, and $49.3 \%$ were men.

\subsubsection{Procedure:}

125 thesis students took part in the TURBAHAR field study. Each student has reached people living in the regions where they are or can be reached. All employees were accountable to a senior regional representative. All employees were responsible to the faculty. Participants in the study were selected from individuals in various fields of study such as schools, municipal buildings, private companies, and public areas such as reeve, common public areas, courses, charities. Potential participants were asked whether they would like to participate by explaining the purpose and introduction of the research. Individuals aged 18 years and over were included in the study. Following the signing of the informed volunteer form, questionnaires were delivered to the participants in a booklet containing data collection tools. The volunteers completed the questionnaires individually and returned them to the researcher. Instructions regarding the scales were given both verbally and in writing. During the application, the questions that volunteers to ask for help were answered. The survey took approximately 45 minutes to complete. There is no time limit for filing the scales since the implementation is long for participants to respond in busy working environments. After the application of the survey, the participants had informed, and the researcher's contact details had shared for reaching out. The study was approved by the Üsküdar University Non-Invasive Research Ethics Committee.

The teams started their field missions in July 2018. Data collection and data entry were completed in October 2018. A single repository of all data was created and loaded into the SPSS 21 Program. The data were edited. The analysis was done on 24494 participants, including invalid and excluded from the sample.

\subsection{Data Collection Tools Used in Research:}

Socio-Demographic Information Form, Behavior Impact Load Form, and Brief Symptom Inventory (BSI) were used in the study. All participants signed a consent form on the first page of the booklet, which they voluntarily declared. The consent form signed by the participants was explained briefly and the participants were asked to answer the scales and questionnaires.

\subsubsection{Sociodemographic Information Form (SIF):}

The participants included age, education, marital status, gender, number of children, number of employees, smoking, alcohol, psychiatric treatment application history. Education levels are selected as literate, not literate, primary school graduate, secondary school graduate, high school graduate, university, and master, and marital status are married, single, and separated. 


\section{Examination of the Predictability of Psychological and Sociodemographic Variables among Early Emerging Adulthood and Late Emerging Adulthood Seeking Mental Health Treatment}

If the participant smokes, it has the amount of smoking $(0-10,11-20,21-40$, more than 41$)$ and the years of smoking $(0-5,6-10$, $11-15,16-20$, and more than 21 years). Whether alcohol is present, how often it is used (1-2 times a month, 1-2 times a week, and almost every day).

\subsubsection{Brief Symptom Inventory (BSI):}

It is a 53-item self-report measure developed by Derogatis [11] and its scores range from 0 to 212 . Each item is scored 0 to 4. High scores taken from the scale indicate the frequency of an individual's symptoms. Turkish adaptation was conducted through three separate studies in Turkey by Sahin and Durak [12].

In the original form of the scale, there are nine subscales which are obsessive-compulsive disorder, phobic anxiety, hostility, anxiety disorder, psychoticism, interpersonal sensitivity, depression, somatization and paranoid thoughts. Cronbach's alpha internal consistency coefficient of the subscales was in the range of $0.71-0.85$. Test-retest reliability is in the range of $r=0.68$ 0.91. [13]

\subsubsection{Positive-Negative Emotion Status Scale:}

The Positive and Negative Affect Schedule (PANAS) is a scale that examines the mood with positive and negative dimensions developed by Watson et al. [14]. Positive emotion; a feeling, negative emotion in a total of 10 items, excited, strong, enthusiastic, proud, alert, inspired, determined, active, concerned and careful; Distressed, unhappy, guilty, frightened, hostile, irritable, embarrassed, irritable, anxious, and scared constitutes another dimension in 10 items. By Watson et al., The reliability coefficients of the positive emotion dimension and negative emotion dimension were found to be .88 and .87 , respectively.

\subsubsection{Personal Well-being Index:}

Personal Well-Being Index is a self-report scale including eight domains determined by the International Wellbeing Group [15], the standard of living, personal health, achieving in life, personal relationships, personal safety, community-connectedness, future security and spirituality. PWI, which was adapted to Turkish by Meral [16], consists of 8 items which are all positive, and the maximum score is 80 .

\subsection{Statistical Analysis:}

Data were analyzed using SPSS - 21.

Education, gender, marital status, number of children, and age variables that may affect psychological symptoms and Logistic Regression was used to estimate the relationship between the Brief Symptom Inventory and the variables used in the study. Total and subscale scores have obtained from independent variables, and scales were included in the model. $\mathrm{P}$ values less than 0.05 were considered as independent risk factors.

\section{RESULTS}

Table 1. Descriptive Statistics of Participants Gender Variable

\begin{tabular}{llll}
\hline & & $\mathrm{n}$ & $\%$ \\
\hline \multirow{3}{*}{ Gender } & Men & 6247 & 48,3 \\
& Woman & 6695 & 51,7 \\
& Total & 12942 & 100,0 \\
\hline
\end{tabular}

Table 2. Descriptive Statistics of Demographic Variables of Men and Women

\begin{tabular}{|c|c|c|c|c|c|c|c|}
\hline & & \multicolumn{2}{|l|}{ Men } & \multicolumn{2}{|c|}{ Woman } & \multicolumn{2}{|l|}{ Total } \\
\hline & & $\mathrm{n}$ & $\%$ & $\mathrm{n}$ & $\%$ & $\mathrm{n}$ & $\%$ \\
\hline \multirow[t]{3}{*}{ Going to Psychiatry } & Yes & 5005 & 80,1 & 4946 & 73,9 & 9951 & 76,9 \\
\hline & No & 1242 & 19,1 & 1749 & 26,1 & 2991 & 23,1 \\
\hline & Total & 6247 & 100,0 & 6695 & 100,0 & 12942 & 100,0 \\
\hline \multirow{7}{*}{ Education } & Literate & 80 & 1,3 & 85 & 1,3 & 165 & 1,3 \\
\hline & Elementary school & 76 & 1,2 & 44 & 0,7 & 120 & 0,93 \\
\hline & Secondary school & 332 & 5,3 & 212 & 3,2 & 544 & 4,2 \\
\hline & High school & 1652 & 26,4 & 1399 & 20,9 & 3051 & 23,6 \\
\hline & University & 3783 & 60,6 & 4476 & 66,9 & 8259 & 63,8 \\
\hline & Master & 321 & 5,1 & 476 & 7,1 & 797 & 6,2 \\
\hline & Total & 6244 & 100,0 & 6692 & 100,0 & 12936 & 100,0 \\
\hline \multirow[t]{3}{*}{ Marital status } & Married & 735 & 11,8 & 1144 & 17,1 & 1879 & 14,5 \\
\hline & Single & 5471 & 87,6 & 5486 & 81,9 & 10957 & 84,7 \\
\hline & Divided & 38 &, 6 & 59 & 0,9 & 97 & 0,8 \\
\hline
\end{tabular}


Examination of the Predictability of Psychological and Sociodemographic Variables among Early Emerging Adulthood and Late Emerging Adulthood Seeking Mental Health Treatment

\begin{tabular}{|c|c|c|c|c|c|c|c|}
\hline & Total & 6244 & 100,0 & 6689 & 99,9 & 12933 & 100,0 \\
\hline \multirow[t]{4}{*}{$\begin{array}{l}\text { Number } \\
\text { of children }\end{array}$} & 0 & 5821 & 93,2 & 6085 & 90,9 & 11906 & 92,0 \\
\hline & 1 & 287 & 4,6 & 417 & 6,2 & 704 & 5,4 \\
\hline & 2> & 138 & 2,4 & 193 & 3,8 & 331 & 2,6 \\
\hline & Total & 6247 & 100,0 & 6695 & 100,0 & 12941 & 100,0 \\
\hline \multirow[t]{4}{*}{ Use of Cigarette } & Yes & 3479 & 55,7 & 2151 & 32,1 & 5630 & 43,5 \\
\hline & No & 2465 & 39,5 & 4317 & 64,5 & 6782 & 52,0 \\
\hline & Stopped & 302 & 4,8 & 218 & 3,3 & 520 & 4,0 \\
\hline & Total & 6246 & 100,0 & 6686 & 99,9 & 12932 & 100,0 \\
\hline \multirow[t]{4}{*}{ Use of Alcohol } & Yes & 2903 & 46,5 & 1976 & 29,5 & 4879 & 37,7 \\
\hline & No & 3033 & 48,6 & 4595 & 68,6 & 7628 & 58,9 \\
\hline & Stopped & 310 & 5,0 & 124 & 1,9 & 434 & 3,4 \\
\hline & Total & 6246 & 100,0 & 6695 & 100,0 & 12941 & 100,0 \\
\hline \multirow[t]{5}{*}{$\begin{array}{l}\text { Number of Cigarettes } \\
\text { Smoked per Day }\end{array}$} & 0 & 2675 & 42,8 & 4449 & 66,5 & 7124 & 55,5 \\
\hline & $0-10$ & 1182 & 18,9 & 1322 & 19,7 & 2504 & 19,5 \\
\hline & $11-20$ & 1749 & 28,0 & 733 & 10,9 & 2482 & 19,3 \\
\hline & $21-40$ & 521 & 8,3 & 125 & 1,9 & 646 & 5,0 \\
\hline & More than 41 & 77 & 1,2 & 13 &, 2 & 90 & 0,7 \\
\hline \multirow[t]{5}{*}{$\begin{array}{l}\text { Frequency of Alcohol } \\
\text { Use }\end{array}$} & I Don't Use & 3328 & 53,3 & 4707 & 70,3 & 8035 & 62,1 \\
\hline & 1-2 per Month & 1661 & 26,6 & 1467 & 21,9 & 3128 & 24,2 \\
\hline & 1-2 per Week & 922 & 14,8 & 429 & 6,4 & 1351 & 10,4 \\
\hline & $\begin{array}{l}\text { Almost } \\
\text { Every Day }\end{array}$ & 336 & 5,4 & 92 & 1,4 & 428 & 3,3 \\
\hline & Total & 6247 & 100,0 & 6695 & 100,0 & 12942 & 100,0 \\
\hline
\end{tabular}

When the variable of the distribution of the psychiatric treatment status has examined according to gender, it was seen that 19.9\% $(\mathrm{n}=1242)$ of the males received psychiatric treatment and $80.1 \%(\mathrm{n}=5005)$ did not receive treatment. In females, $26.1 \%$ $(\mathrm{n}=1749)$ had psychiatric treatment; It was reported that 73.9\% $(\mathrm{n}=4946)$ did not receive psychiatric treatment.

When the educational level of the participants was examined, literacy rate was $1.3 \%(\mathrm{n}=80)$ for boys, $1.2 \%(\mathrm{n}=76)$ for primary school, $5.3 \%(\mathrm{n}=332)$ for secondary school, $26.4 \%$ for high school graduates $(\mathrm{n}=1652) .50 .6 \%(\mathrm{n}=3783)$ of university graduates and $5.1 \%(\mathrm{n}=321)$ of graduate students. For women, literacy rate was $1.3 \%(\mathrm{n}=85)$, primary school graduates were $0.7 \%(\mathrm{n}=44)$, secondary school graduates were $3.2 \%(\mathrm{n}=212)$, high school graduates were $20.9 \%(\mathrm{n}=1399)$, university $66.9 \%$ of the graduates $(n=4476)$ and $7.1 \%$ of the graduate graduates $(n=476)$.

According to the frequency distribution of the marital status variable of the participants, it is seen that $11.8 \%(\mathrm{n}=735)$ are married, $87.6 \%(\mathrm{n}=5471)$ single and $0.6 \%(\mathrm{n}=38)$ are separated in males. In women, $17.1 \%(\mathrm{n}=1144)$ were married, $81.9 \%(\mathrm{n}$ $=5486)$ single and $0.9 \%(\mathrm{n}=59)$ were separated.

For the number of children variable, the rate of $93.2 \%(\mathrm{n}=5821)$ in boys has no children. $4.6 \%(\mathrm{n}=281)$ of one child and $2.4 \%(\mathrm{n}=138)$ of two children and more children. It is seen that $90.9 \%(\mathrm{n}=6085)$ of women do not have children. In addition, $6.2 \%(n=417)$ had one child and $3.8 \%(n=193)$ had two children or more.

Considering the variables of smoking $55.7 \%$ of men $=3479)$ do not smoke. $39 \%(\mathrm{n}=2465)$ did not smoke and $4.8 \%(\mathrm{n}=302)$ quit smoking. In women, $32.1 \%(\mathrm{n}=2151)$ were smokers. 64.5\% $(\mathrm{n}=4317)$ did not smoke and $3.3 \%(\mathrm{n}=218)$ quit smoking.

In respect of the alcohol use variable, 46.5\% $(\mathrm{n}=2903)$ of men do not use alcohol. 48.6\% $(\mathrm{n}=3033)$ did not use alcohol and $5 \%(\mathrm{n}=310)$ stopped drinking. In women, $29.5(\mathrm{n}=1976)$ were using alcohol. 68.6\% $(\mathrm{n}=4595)$ did not use alcohol and $1.9 \%(\mathrm{n}$ $=124)$ stopped using alcohol.

42.8\% ( $\mathrm{n}=2675$ ) of women and men did not specify the number of cigarettes smoked per day. $18.9 \%(\mathrm{n}=1182)$ were between $0-10,28 \%(\mathrm{n}=1749)$ were between $11-20,8.3 \%$ were between $21-40$ and $1.2 \%$ were $(\mathrm{n}=77)$ stated that they smoked 41 or more cigarettes. $66.5 \%$ of the women $(\mathrm{n}=4449)$ did not specify the number. $19.7 \%(\mathrm{n}=1322)$ were between 0 and $10,10.9 \%(\mathrm{n}=733)$ were between 11 and 20,1.9\% $(n=125)$ were between 21 and $40 \% .0 .2(n=13)$ reported that they smoked 41 or more cigarettes. When the distribution of the prevalence of alcohol use in women and men was examined, 53.3\% ( $\mathrm{n}=3328)$ of men did not specify the frequency. $26.6 \%(\mathrm{n}=1661) 1-2$ times a month, $14.8 \%(\mathrm{n}=922) 1-2$ times a week, $5.4 \%(\mathrm{n}=336)$ alcohol almost 
Examination of the Predictability of Psychological and Sociodemographic Variables among Early Emerging Adulthood and Late Emerging Adulthood Seeking Mental Health Treatment

daily have taken. In women, $70.3 \%(n=4707)$ did not specify frequency. $21.9 \%(n=1467) 1-2$ times a month, 6.4\% $(n=429) 1-2$ times a week and $1.4 \%(\mathrm{n}=92)$ almost daily alcohol received.

Table 3. Logistic Regression Analysis Results of Sociodemographic and Psychological Variables of Men Receiving Psychiatric Treatment

\begin{tabular}{|c|c|c|c|c|c|c|c|c|c|c|}
\hline & & \multirow[t]{2}{*}{ Gender } & \multirow[t]{2}{*}{$B$} & \multirow[t]{2}{*}{$S H$} & \multirow[t]{2}{*}{ Wald } & \multirow[t]{2}{*}{$s d$} & \multirow[t]{2}{*}{$p$} & \multirow[t]{2}{*}{$\begin{array}{l}\operatorname{Exp} \\
(B)\end{array}$} & \multicolumn{2}{|c|}{$\begin{array}{l}\text { Exp (B)Level of } \\
\text { Confidence }\end{array}$} \\
\hline & & & & & & & & & Upper & Lower \\
\hline \multirow[t]{13}{*}{ Men } & 1 & KSE_Anxiety & ,009 & ,008 & 1,394 & 1 & ,238 & 1,010 & ,994 & 1,026 \\
\hline & & KSE_Depression & ,022 & ,007 & 10,663 & 1 &, $001 * *$ & 1,022 & 1,009 & 1,035 \\
\hline & & KSE_Negatif self &,- 010 & ,008 & 1,425 & 1 & ,233 & ,990 & ,975 & 1,006 \\
\hline & & KSE_Somatizasyon & ,007 & ,009 &, 512 & 1 & ,474 & 1,007 & ,989 & 1,025 \\
\hline & & KSE_Hostilite & ,036 & ,009 & 17,032 & 1 & $<0,001 * * *$ & 1,037 & 1,019 & 1,055 \\
\hline & & KİO &,- 007 & ,002 & 8,666 & 1 &, $003 * *$ & ,993 & ,988 & ,998 \\
\hline & & PNDOPD & ,000 & ,004 &, 005 & 1 & ,946 & 1,000 & ,992 & 1,009 \\
\hline & & PNDOND & ,000 & ,006 &, 000 & 1 & ,993 & 1,000 & ,989 & 1,011 \\
\hline & & Education & ,081 & ,045 & 3,248 & 1 & ,072 & 1,084 & ,993 & 1,183 \\
\hline & & Cigarette & ,101 & ,032 & 9,782 & 1 &, $002 * *$ & 1,106 & 1,038 & 1,178 \\
\hline & & Alcohol & ,299 & ,036 & 68,673 & 1 & $<, 001 * * *$ & 1,349 & 1,257 & 1,448 \\
\hline & & Age & ,002 & ,010 &, 050 & 1 & ,823 & 1,002 & ,982 & 1,023 \\
\hline & & (Fixed) & $-2,534$ &, 335 & 57,222 & 1 & ,000 & ,079 & & \\
\hline
\end{tabular}

In Table 3, when the sociodemographic and psychological variables of men have examined with previous visits to psychiatry, the number of cigarettes smoked per day $(B=, 101 ; p<0.05)$, the frequency of alcohol use $(B=, 299 ; p<0.01)$, depression $(B=$, 022; $\mathrm{p}<0.05)$, were significantly predicted by hostility $(\mathrm{B}=, 036 ; \mathrm{p}<0.01)$ and personal well-being $(\mathrm{B}=-, 007 ; \mathrm{p}<0.05)$. According to the results, the high number of cigarettes used per day, the high frequency of alcohol use, high depression scores, and low levels of personal well-being predicted to go to psychiatry. According to the findings, men who did not receive psychiatric treatment were more likely to have higher alcohol and cigarette smoking, more hostility and depression symptoms, and lower levels of personal well-being.

Table 4. Logistic Regression Analysis Results of Sociodemographic and Psychological Variables of Women Receiving Psychiatric Treatment

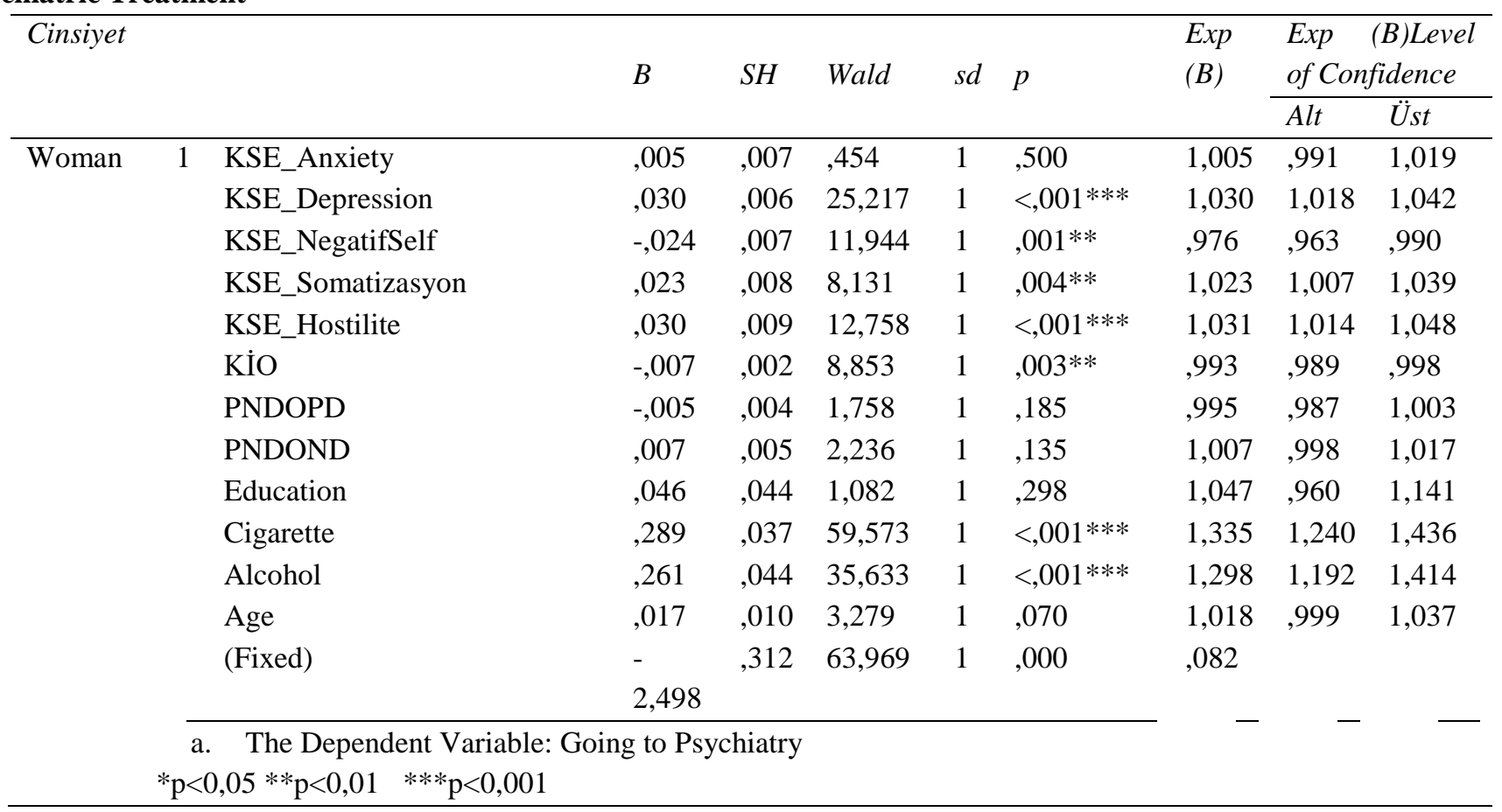




\section{Examination of the Predictability of Psychological and Sociodemographic Variables among Early Emerging Adulthood and Late Emerging Adulthood Seeking Mental Health Treatment}

In Table 4, when the sociodemographic and psychological variables of women were examined in terms of their previous psychiatric status, the number of cigarettes smoked per day $(B=0.28 ; p<0.01)$ and the frequency of alcohol use $(B=0.26 ; p$ $<0.01)$, depression $(B=0.03 ; p<0.001)$, negative self $(B=-0.02 ; p<0.01)$, somatization $(B=0.02 ; p<0.01)$, hostility $(B)=0.03$; $\mathrm{p}<0.001$ ), and personal well-being $(\mathrm{B}=-0.07 ; \mathrm{p}<0.01)$ ). According to the results, the high number of cigarettes used per day, the high frequency of alcohol use, high scores of depression, somatization and hostility, and low levels of negative self and personal well-being predicted to go to psychiatry. According to the findings, smoking and alcohol use, depressive symptoms, hostility, and somatization symptoms were higher among women who did not receive psychiatric treatment. Personal well-being and low probability of negative self-symptoms are significantly higher.

\section{DISCUSSION}

When the findings of the study which are the problem of the study, were related to the relationship between psychological factors, alcohol use and cigarette smoking, and male and female use, high depression and hostility scores, and low personal well-being scores, significantly explain the application. In women, smoking and alcohol use, high levels of depression, somatization and hostility scores, and low levels of personal well-being and negative self-scores were found to significantly predict the status of the psychiatric application.

According to the results, psychiatric status in both young adult men and women was found to be related to alcohol use and smoking, depression, hostility, and personal well-being. In their study by Hansen and Hoye [9], they stated that age can be a decisive factor in applying to psychiatry and the rate of admission decreases with age. However, it was found that somatization and negative self-scores in women also predicted psychiatric consultations. Keskin et al. [17] found that among the mental health disorders, $64 \%$ of the participants with mood disorders, $67 \%$ of the patients with anxiety disorders, and $67 \%$ of the patients with somatoform disorders were willing to receive psychiatric treatment. In other studies conducted on the level of utilization of mental health services by women and men, it was found that women have benefited from mental health services more than the general population. However, it suggested that as the age gets older, the benefit levels of men and women approach each other. [18] On the other hand, in another study conducted by Gagne et al. [19], the level of depression was found as a common variable predicting the psychiatric status of men and women, a study conducted in Canada by family physicians and mental health experts evaluated their applications. According to the results, it was seen that males had more applications than females. Mental health services were found to be affected by variables such as low-income level in men, being younger in women, and the presence of social support. In a different study conducted in our country, Gür and Küçük [10] found that low socioeconomic status was related to women's attitudes towards mental health; low socioeconomic level of women's attitudes was more positive. In another study conducted by Keskin et al. [17], the comparison between the distribution of mental health problems by gender and the level of utilization of mental health services have done. When the prevalence of psychiatric disorders has examined, it was found that anxiety, mood, and somatoform disorders were higher in women than in alcohol and substance use disorders. In addition, when the state of seeking help for psychiatric disorders has examined, it found that the highest proportion of people diagnosed with the somatoform disorder could benefit from mental health services.

\section{RESULTS}

In this study, men's and women's level of differentiation of psychiatric symptoms in psychological symptoms was examined. Based on the previous studies which suggested that treatment-seeking and psychiatric status differ for gender, the TURBAHAR study, including 9 different regions and psychiatric help for the young adult men and women are discussed in this study in predictive psychological variables. Firstly, participant's descriptive statistics regarding the demographic variables had given in the study. According to the frequencies, the number of males and females is close; however, female participants were slightly more likely than men. According to the variable of education level, the ratio of education level university students is highest among male and female participants. According to the variable of education level, the ratio of education level university students is highest among male and female participants. For the marital status variable, the ratio of single participants, which is thought to be consistent with the age range, is the highest. In parallel to this result, the number of participants who do not have children is the highest. When the variables related to smoking and alcohol use of men and women had considered, the rate of men smoking and drinking is higher than that of women. However, the majority of respondents reporting alcohol use reported that they consume alcohol once or twice a month. It had observed that the number of cigarettes smoked per day was 11 to 20 in both male and female participants.

According to the results of the study, alcohol and cigarette smoking, depression, hostility, and personal well-being levels are among the variables predicting the psychiatric status of men and women. In addition, somatization and negative self are among the variables explaining women applying to psychiatry. According to this result, it is thought that symptom awareness and sociocultural factors may play a role in the differentiation of the level of utilization of mental health services by men and women. It is envisaged that the levels of access to mental health services should be improved, and gender differences should be eliminated. 


\section{Examination of the Predictability of Psychological and Sociodemographic Variables among Early Emerging Adulthood and Late Emerging Adulthood Seeking Mental Health Treatment}

It is thought that informing men and women about the fear of stigmatization, which stated to prevent the use of mental health services, is important in the development of healthy behaviours.

\section{REFERENCES}

1) World Health Organization. (2013). WHO methods and data sources for global burden of disease estimates 2000-2011. World Health Organization. 2013.

2) Kessler R.C., Berglund P., Demler O., Jin R., \& Merikangas K.R. (2005). Lifetime prevalence and age of-onset distributions of DSM-IV disorders in the national comorbidity survey replication. Arch Gen Psychiatry. 62(6):593-602.

3) Gulliver A., Griffiths K.M., \& Christensen H. (2010). Perceived barriers and facilitators to mental health help-seeking in young people: a systematic review. BMC Psychiatry. 10:113. doi: 10.1186/1471-244X-10-113.

4) Rogler L.H, \& Cortes D.E. (1993): Help-seeking Pathways: A Unifying Concept in Mental Health Care. American Journal of Psychiatry. 150(4):554-561.

5) Mechanic, D. (1962). Students under stress: A study of the social psychology of adaptation.

6) Sherman, B. J., McRae-Clark, A. L., Baker, N. L., Sonne, S. C., Killeen, T. K., Cloud, K., \& Gray, K. M. (2017). Gender differences among treatment-seeking adults with cannabis use disorder: Clinical profiles of women and men enrolled in the achieving cannabis cessation-evaluating $\mathrm{N}$-acetylcysteine treatment (ACCENT) study. The American journal on addictions, 26(2), 136-144. doi:10.1111/ajad.12503

7) Drapalski, A., Bennett, M., \& Bellack, A. (2011). Gender differences in substance use, consequences, motivation to change, and treatment seeking in people with serious mental illness. Substance use \& misuse, 46(6), 808-818. doi:10.3109/10826084.2010.538460

8) Parslow R. \& Jorm A. (2000). Who uses mental health services in Australia? An analysis of data from the National Survey of Mental Health and Wellbeing. Australian and New Zealand Journal of Psychiatry. 39, 997-1008

9) Hansen, A. H., \& Høye, A. (2015). Gender differences in the use of psychiatric outpatient specialist services in Tromsø, Norway are dependent on age: a population-based cross-sectional survey. BMC health services research, 15, 477.

10) Gur, K., \& Kucuk, L. (2016). Females' Attitudes Toward Mental Illness: A Sample From Rural Istanbul, Turkey. Iranian Red Crescent medical journal, 18(5), e22267.

11) Derogatis, L. R. (1992). The Brief Symptom Inventory (BSI): Administration, scoring and procedures manual II. Townson, MD: Clinical Psychometrics Research.

12) Şahin, N. H., \& Durak, A. (1994). Kısa semptom envanteri: Türk gençleri için uyarlanması. Türk Psikoloji Dergisi, 9(31), 44-56.

13) Savaşır, I., \& Şahin, N. H. (1997). Boyun eğici davranışlar ölçeği. Bilişsel-davranışçı terapilerde değerlendirme: Sık kullanılan ölçekler. Ankara: Özyurt Matbaacılık.

14) Watson, D., Clark, L. A., \& Tellegen, A. (1988). Development and validation of brief measures of positive and negative affect: the PANAS scales. Journal of personality and social psychology, 54(6), 1063.

15) International Wellbeing Group. (2006). Personal wellbeing index.

16) Meral, B. F. (2014). Psychometric properties of Turkish form of the Personal Well-Being Index-Adult. The Journal of Happiness \& Well-Being, 2, 119-31.

17) Keskin, A., Ünlüoğlu, İ., Bilge, U., \& Yenilmez, Ç. (2012). Ruhsal Bozuklukların Yaygınlığı, Cinsiyetlere Göre Dağıllımı ve Psikiyatrik Destek Alma ile İlişkisi, Archives of Neuropsychiatry, 50, 344-351.

18) Smith, K.L.W.M.F., Moinedding, R., Dunn J.R., Lu H., \& Cairney J., \& Glazier R.H. (2013). Gender differences in mental health service utilization among respondents reporting depression in a natinal health survey. Health (N Y), 5(10):1561-1571.

19) Gagne, S., Vasiliadis, H. M., \& Préville, M. (2014). Gender differences in general and specialty outpatient mental health service use for depression. BMC Psychiatry, 14, 135. 